\title{
The promotion of road safety by healthcare professionals in South Africa
}

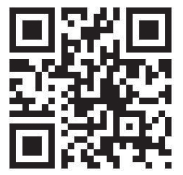

South Africa (SA), as this issue of the SAMJ will highlight, has one of the highest levels of death through injury in the world. We are (or have become) an extremely violent society and much of the injury we experience as a nation derives from interpersonal violence. However, another large component is accidental injury, and within the sphere of accidental injury, traffic death and injury levels in SA stand out internationally.

According to the World Health Organization (WHO), SA is 1 of 10 countries in the world that are collectively responsible for generating some $62 \%$ of global traffic deaths annually. ${ }^{[1]}$ The other countries that feature in the top 10, including India, China and the United States, do so mainly because of their huge populations. SA tops the list because our roads and driving behaviour result in more deaths per 100000 population than most other countries of comparable population size and economic development.

Every emergency room in SA sees high numbers of injured drivers, pedestrians and passengers through its doors every year. Emergency centre staff know first-hand the long-term toll that crashes take on individuals and their families. The majority of SA citizens, however, appear strangely indifferent to high death rates on our roads. In the absence of any convincing leadership around reducing road casualties, this is partly to be expected. However, another reason for our national indifference lies in simple ignorance.

We have no real conviction that things can improve because we are not aware of how they have changed so dramatically in other parts of the world. We have no expectation that anything we do as individuals can make any difference to this national crisis. We have personally survived countless traffic journeys without injury and our familiarity with 'dangerous' traffic conditions has bred a strong sense of complacency.
Until national government prioritises casualty reduction efforts, it is unlikely that we will see improvements in education and awareness. However, attitudes to accident prevention can be changed and medical practitioners can play a leading role in this. While we cannot decrease the number of crashes that take place overnight, we can rapidly reduce the risk of serious injury or death in the event of a crash. Here, the medical profession can play a major role.

\section{How high is the risk of being killed or injured?}

Approximately 14000 people are killed and over 100000 seriously injured every year in traffic collisions in SA. ${ }^{[2]}$ The fatality risk (per 100000 population) is estimated in the WHO 2009 status report to be 33.2, against figures commonly below 10 for countries in Europe and North America. As such, SA residents are exposed to some of the highest risks of premature mortality through traffic injury. Traffic injuries have been identified as the top cause of premature death in children between the ages of 5 and 14 years and the second highest cause in children between 15 and 18 years. ${ }^{[3]}$ In the 2000 Burden of Disease (BoD) study, traffic injuries ranked 9th at national level but 5 th for Gauteng and 6th for the Western Cape. ${ }^{[4]}$ Road traffic deaths are slightly lower than homicides in urban areas but outstrip homicide as a cause of non-natural deaths in non-urban areas. The results of the 2009 BoD study have not yet been released but indications are that traffic injuries are at least as horrific as they were a decade ago.

\section{In-vehicle protection systems}

Recent developments in vehicle technology have vastly improved the safety of vehicle occupants; advances in braking, steering and road handling, 
in airbag technology and advanced warnings systems have changed the likelihood of crashes (for new model vehicles) and greatly improved the survivability of occupants in the event of a crash at low or moderate speed ( $<80 \mathrm{~km} /$ hour). Despite huge investment and the development of safe car systems, however, the single most effective apparatus preventing injury is the seatbelt. What some may consider an outdated technology frequently determines the likelihood of life or death.

Since the 1980s, several reviews of seatbelt effectiveness have been carried out. Without exception, all agree that seatbelt use is the most significant way to protect vehicle occupants from injury in a crash. Seatbelt use reduces the probability of being killed by $40 \%-50 \%$ for drivers and front seat passengers and approximately $25 \%$ for passengers in rear seats. ${ }^{[5]}$

Seatbelts work in 3 ways: $(i)$ they prevent ejection from a vehicle (ejection results in a $5-8$ times higher chance of death compared with non-ejection); (ii) they prevent an occupant from being flung forward and hitting the dashboard, the seat in front of them or another occupant; and (iii) they increase the time over which the impact exerts itself on the occupant, thereby reducing the risk of internal injury.

While children are also protected by seatbelts, they have specific physiological limitations that render them particularly vulnerable to serious injury. The skulls of infants are extremely malleable until around 24 months, so that even low levels of force can cause cranial deformation and brain injury. The infant/child ribcage is similarly flexible and chest and abdominal organs are poorly protected. Young children are most effectively protected when restrained in a way that distributes the restraint forces as widely as possible over the body. For the youngest children, this requires that they be seated in a rear facing position.

Not surprisingly, given the physical limitations of children, research shows that child restraint systems are significantly better at reducing fatality risk to children than conventional seatbelts. In terms of the effectiveness of age-appropriate child restraint systems, Abrogast et al. ${ }^{[6]}$ found that the risk of serious injury was $78 \%$ lower for children in forward-facing restraints than in seatbelts. Other research on the effectiveness of child restraint systems has found them to reduce fatal injury by $74 \%$ for infants $<1$ year old. ${ }^{[7]}$ Elliot et al ${ }^{[8]}$ examined the differences in mortality rates between children aged 2 and 6 years in conventional seatbelts and child restraint systems and found that while seatbelts have been shown to reduce fatalities, children in child restraint systems had a $28 \%$ lower mortality risk than those in conventional seat belts. They concluded that child restraint systems offer a considerable safety advantage over seat belts alone.

\section{Seatbelt use in SA}

Why, in the face of the extraordinary success in reducing deaths and serious injuries, do South Africans still demonstrate the most dismal of seatbelt wearing rates? The answer, as suggested earlier, is most likely a combination of lack of national leadership and ignorance. Seatbelt use is not enforced by traffic officials and, in fact, many officials themselves flaunt seatbelt laws. The law is very clear - all adult occupants (whether in the front- or back-seat) are obliged to wear seatbelts if they are fitted to the vehicle; it is the driver's legal responsibility to ensure that the passengers are 'buckled up'.

As far as children's use of seatbelts is concerned, the SA legislation is less clear and in fact dismally fails to ensure adequate protection for all children. Only children older than 3 years old are currently included under the legislation and are only obliged to utilise seatbelts where there are enough present in a vehicle. ${ }^{[9]}$ The SA legislation thus renders it lawful for children to travel in a vehicle without any form of restraint - a situation almost unique in the world. Furthermore, babies and young children are commonly, and legally, held in the arms of adult passengers in the mistaken belief that in the event of a collision the child will be safely retained in the adult's arms. This is of course a physical impossibility given the force of any impact, when the weight and velocity of an adult body will convert into a force of potentially lethal magnitude. Young children may be literally crushed to death by the adults holding them.

\section{Role of healthcare professionals}

Prevention of traffic injury is seldom regarded as the responsibility of healthcare professionals. Most countries, including our own, define traffic injuries as the responsibility of the Department of Transport, rather than the Department of Health (by the same token domestic violence is considered the domain of the Department of Public Safety). The end result is that healthcare professionals are responsible for dealing with the consequences of traffic collisions, but not for ensuring their prevention. This is counterintuitive, given that worldwide healthcare professionals have had remarkable success in preventing social health issues such as smoking, obesity and indeed traffic injuries (by promoting seatbelt use). The advice of family practitioners and medical specialists carries significant weight for many citizens. If every healthcare worker, whether general practitioner or paediatrician or nurse, drummed home the value of seatbelts and the absolute necessity of child restraints, the battle against road safety apathy would begin.

\section{Conclusion}

Seatbelts and child restraint systems cannot prevent all deaths or injuries, not least because some collisions occur at such speed that even the most sophisticated safety features are rendered ineffective. The context in which they work is not ideal - not all vehicles have seatbelts (public transport vehicles are often the worst culprits) and our legislation, as discussed already, omits young children.

There is ample evidence, however, that adherence to the laws that compel seatbelt use has led to an average $40 \%-50 \%$ reduction in traffic deaths and injuries across the globe. This trend is not beyond our reach in SA, but to get there we need to find some way of shifting public attitudes to seatbelt use.

One possible starting point lies with healthcare professionals in this country. If medical professionals committed not only to the personal use of seatbelts for themselves and their families, but also to the active encouragement of seatbelt use among their patients, we would see an immediate impact on the number of people killed or injured on our roads. There is a very real window of opportunity for healthcare professionals to engage proactively and positively in road safety in this country.

\section{Marion Sinclair \\ Co-ordinator, Road Safety Research, Department of Civil Engineering, Stellenbosch University, Cape Town, South Africa}

Corresponding author: M Sinclair (msinclair@sun.ac.za)

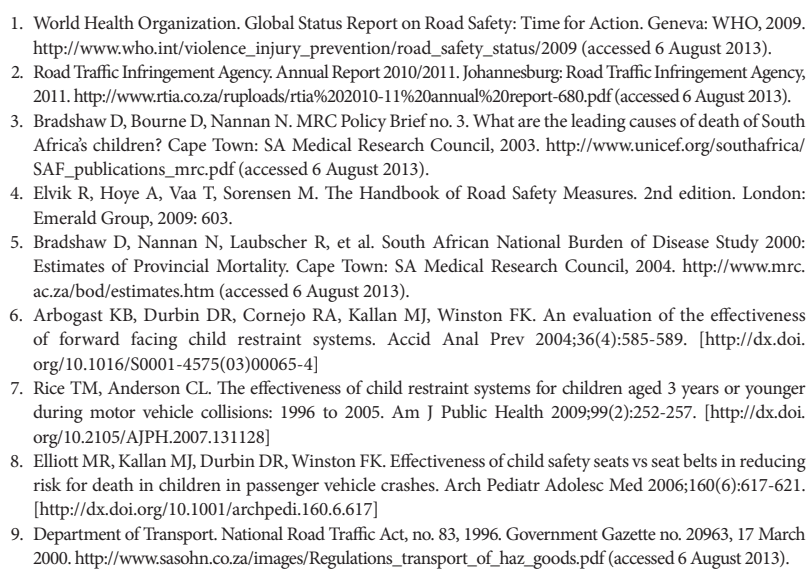
http://www.who.int/violence_injury_prevention/road_safety_status/2009 (accessed 6 August 2013). 2. Road Traffic Infringement Agency. Annual Report 2010/2011. Johannesburg: Road Traffic Infringement Agency 2011. http://www.rtia.co.za/ruploads/rtia\%202010-11\%20annual\%20report-680.pdf (accessed 6 August 2013). 3. Bradshaw D, Bourne D, Nannan N. MRC Policy Brief no. 3. What are the leading causes of death of South Africa’s children? Cape Town: SA Medical Research Council, 2003. http://www.unicef.org/southafrica/ SAF_publications_mrc.pdf (accessed 6 August 2013).

4. Elvik R, Hoye A, Vaa T, Sorensen M. The Handbook of Road Safety Measures. 2nd edition. London: Emerald Group, 2009: 603.

Bradshaw D, Nannan N, Laubscher R, et al. South African National Burden of Disease Study 2000: Estimates of Provincial Mortality. Cape Town: SA Medical Research Council, 2004. http://www.mrc. ac.za/bod/estimates.htm (accessed 6 August 2013)

6

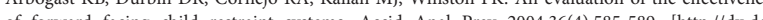
of forward facing child restraint systems. A org/10.1016/S0001-4575(03)00065-4]

Rice TM, Anderson CL. The effectiveness of child restraint systems for children aged 3 years or younge during motor vehicle collisions: 1996 to 2005. Am J Public Health 2009;99(2):252-257. [http://dx.do org/10.2105/AJPH.2007.131128]

8. Elliott MR, Kallan MJ, Durbin DR, Winston FK. Effectiveness of child safety seats vs seat belts in reducing risk for death in children in passenger vehicle crashes. Arch Pediatr Adolesc Med 2006;160(6):617-621. [http://dx.doi.org/10.1001/archpedi.160.6.617]

9. Department of Transport. National Road Traffic Act, no. 83, 1996. Government Gazette no. 20963, 17 March 2000. http://www.sasohn.co.za/images/Regulations_transport_of_haz_goods.pdf (accessed 6 August 2013).

S Afr Med J 2013;103(9):614-615. DOI:10.7196/SAMJ.7335 